\title{
Thinking the curriculum in an inclusive perspective: challenges and opportunities
}

Valentina Pennazio

\begin{abstract}
The present article offers some points of considerations regarding the discovery of new ways to develop the traditionally vertical curriculum into a more inclusive perspective, meeting the needs of the heterogeneous groups of students that, at the moment, are part of the educational environment. With this aim, the concept of inclusion is analyzed, trying to highlight how different visions and interpretations at a European level, determine notable differences in curricular practices and didactics at a national and regional/local level. Among the suggested approaches there are the individualization focused and the personalization focused perspectives. However, it is necessary to consider their feasibility, looking for solutions that merge the two aspects into common paths that can be pursued by each student in a personal way. Talking about an inclusive curriculum, including suggestions, as the one carried out by the Index, led us to think how possible and useful it can be to structure the curriculum in a certain way, so that an inclusive culture can be developed.
\end{abstract}

Keywords: inclusion, curriculum, personalization/individualization, special education needs.

\section{Introduction}

The current educational environment is characterized by a variety of internal needs, determined by the different types of students (e.g. disability, learning disabilities, socio-cultural deprivation, and different cultural backgrounds). Said category, described by the current norms (C.M. 2013) as "Special education need", requires teachers to be willing to rethink their way of teaching both at a design and concrete action level, and to develop educational strategies that enable them to deal with different learning needs. In this way, it

\footnotetext{
${ }^{1}$ Valentina Pennazio is Researcher on Didactics and Special Pedagogy, Department of Education, Cultural Heritage and Tourism, University of Macerata.
} 
would be possible to start a change in the cultural and social "texture" of the class.

Internal cooperation among teachers (even with different subject or roles) and the common search for solutions that respond to everyone's needs is only possible if the cultural frame is inclusive. With the challenges involved in every type of difference for the educational organization, this cultural frame enables to start a researching and thinking process that leads to the formulation of educational answers and individualized, differentiated and personalized didactics. Those didactics, as Ianes (2006) says, need to remain in the "normality" of the school organization and not become a part of a delegation system, a substitutive intervention request or marginalization and isolation of the student from the classroom context.

It is clear from the Curriculum National Indications (2012) that the "school aims need to be defined from the learning person, keeping the originality of the individual path, the definition and the realization of the educational and didactical strategies, which always need to consider the singularity and complexity of every person, his individuality, identity, aspirations and abilities, together with the fragilities typical of every stage of his education".

The emerging pedagogical setting supports the Special Education Need, requiring teachers the availability to reconsider their didactical abilities and enrich them with design strategies and instruments that can go beyond the standardized approach, based on techniques and modalities that strengthened with time.

Teachers are firstly asked to actively overcome the idea of programme to embrace one of the key aspects: predisposing the curriculum (Dovigo, 2014). The development of a curriculum and an inclusive didactics, based on cooperation, openness and creativity is clearly a very challenging activity for teachers.

This article aims to find the best modalities to structure an inclusive curriculum, reconsidering the idea of inclusion, individualization and personalization, while highlighting its actual development in an educational environment.

\section{Inclusion: a new way to think about school}

The idea of inclusion, developed from an Anglo-Saxon idea, has now substituted the idea of integration, becoming a part of the Italian vocabulary from the United Nations Convention about human rights for people with disabilities, approved 13th December 2006 and confirmed by the Italian Parliament with Law 18, 3rd March 2009. 
The concept of inclusion also found space in the Guidelines for educational integration of students with disabilities, 4th August 2010 "New Laws regarding Learning Disabilities in an educational environment". More recent documents, such as the Ministerial Decree of 27th December 2012 "Intervention Instruments of students with special needs and local organization for educational inclusion" and C.M. 2013.

The change from the idea of integration to the idea of inclusion, is not only a change in terms but a cultural modification. In fact, the idea of inclusion is based on the recognition of the importance of the total participation to the school life of each and every student, the valorization of differences, the change in contexts and the transformation of the didactical answer, which needs to become ordinary instead of specialist (Dovigo, 2008).

As a consequence, there is also a difference in the practices of integration and inclusion: the first one requires specific answers to students with disabilities, meaning just the aspect of special needs, without predicting changes in the learning environment; the latter looks for individualized responses for every type of need a student might manifest.

According to Ravaud and Stiker (2000), inclusion is evident when a school is able to compensate the weaknesses of some students, offering adequate answers to their needs in a common environment. In this perspective, inclusion is, both on a practical and a theoretical level, wider that integration. In addition, it requires not only a welcoming scholastic organization, but also one that is capable of dealing with the different types of special needs (Ianes, 2005; Pennazio 2017).

The logic of inclusion is not only developed for students with disabilities, who only represent a part of the complicated net of new special needs, and enables the extension of areas of interest and of care to every student, as they all need educational paths that are individualized/personalized (Ianes, 2005), respectful of their cognitive, emotional and personal characteristics. D'Alessio (2011), states that inclusion is referred to the scholastic, social and political environment: however, the focus is on the school and the way it is structured (pedagogy, validation, curriculum, organization), as a reaction to the diversity of the scholastic population.

According to Booth and Ainscow (2008; 2015), inclusion in education involves a series of actions. First of all, it is important to equally valorize every student and the teaching group, generating an improvement in students' involvement and a reduction in their exclusion linked to culture, curriculum and local communities. Secondly, it is necessary to reform cultures, educational politics and practices, so that they reflect better the differences among the students, making those differences as resources to foster learning, rather than problems that need to be solved. In addition, it is fundamental to empathize 
students' right to be educated in their own communities. Thirdly, it is fundamental to underline the role of schools into building a community and promote values, in addition to improve educational results. The key aspect is to valorize the reciprocal support between the school and the community, accepting that inclusion at school is an aspect of inclusion in society. The focus moves from the individual to his contest and requires the analyses of obstacles to learning and socialization, the support to diversity and the resources that are necessary to support learning and participation (Arcangeli et al., 2016).

\section{Different conceptions of inclusion in Europe}

Recognizing the idea of inclusion build on previous analyses carried out in this area (Dyson, 1999; Cigman, 2007; D'Alessio et al., 2010; D'Alessio \& Watkins, 2009) and highlights how different perspectives through which Europe interprets the concept of change in didactics on a national, regional and/or local level (D'Alessio et al.) ${ }^{2}$.

It is important to understand in which ways this concept is interpreted, as from this interpretation different ways of developing the curriculum, the macro and micro design, arise. As Rouse (2008) and Tremblay (2012) say, even highly effective methods with and inclusive perspective (e.g. cooperative learning, metacognitive approach, and adaptations) might not produce the expected results, if not inserted in a theorical framework that supports the development of an inclusive school. This statement reflects what has already been told by Booth and Ainscow (2008).

Some researchers tried to describe the different notions of educational inclusion, especially Mitchell (2005) found sixteen different interpretations that stretch from the classical Salamanca Declaration (1994), to educating students with disabilities and/or special needs (including excellences), to the one supported by UNESCO $(2008 ; 2009)$ and the European Agency (D'Alessio \& Donnelly, 2013) that focuses on the needed change that needs to be undertaken by schools to deal with the needs of the students (D'Alessio et al.).

It is through a elaboration of the work of Clogh and Corbett (2000), that D'Alessio and others describe five different approaches to inclusion: psychomedical approach, sociological approach, curricular approach, developmental approach, inclusive school approach, disabilities studies approach. The authors state that every single approach needs to be analyzed, as it represents different modalities to organize, handle and interpret schools' responsibilities while

2 D’Alessio S., Balerna C., Mainardi M. file:///C:/Users/User/Downloads/20140725_ modello_inclusivo_ST.pdf, consultato il 25 novembre 2017. 
enabling the understanding of how the path developed, leading now to talk about an inclusive school.

\section{Individualizing or personalizing?}

Inclusive logic implies radical changes in the organizational, didactical, educational structure of the school, so that every students gets access to scholastic, social, cultural and working life leading to the realization of an adequate life plan.

Inclusion is a basic right and it is linked to the idea of belongingness and an education that confers to the school quality elements, such as respecting learning times, higher sensitivity to every form of diversity that is understood a perceived as personal enrichment (Canevaro, 2007).

This way of depicting inclusion leads to a new vision of the curriculum, which is no longer described on a "special" but on a common level. The objective of inclusion is that all students share common experiences, instead of building special curricula, this means that it is necessary to work and modify the general curriculum, spreading and differentiating it as much as possible (Dovigo, 2014). This is possible at a macro-design level, thinking from the start about inclusive strategies and didactical methodologies that can be implemented in daily life (to promote cognitive, affective and social learning). The reflection moves onto micro-design, where curricular and specialized teachers should work side by side to contribute, everyone with his own abilities, to prepare rich and articulated paths, so that every student can take part. How is it possible to do so? Is it possible to consider as many paths as the students in a class?

In order to find an answer to this question, it is necessary to go back to the concept of individualization and personalization, trying to understand which of the two is actually feasible,

The idea of individualization involves a diversification of didactical strategies and teaching paths, so that every student can reach the agreed abilities. The individualized educational action has common aims for the whole class but it changes methodologies depending on the specific characteristics of the students, with the objective of ensuring fundamental competencies of the curriculum, focusing on individual differences and a plurality of dimensions (Baldacci, 2005; Fedeli 2016; Pennazio, 2017). As a consequence, individualized didactics consists of strengthening activities that the student can do to improve specific abilities, even in the area of compensatory strategies and study method. Those activities can be realized both in the phases of individual work and in specific moments in the class, according to the flexibility forms that are required by the current norm (Baldacci, 2005; Fedeli, 2016; Pennazio, 2017). 
The idea of personalization involves flexibility in relation to methodologies and other contextual aspects, with the possibility to set differentiated goals for students depending on their individual needs and the profile of functioning. Personalized educational action has the focus on giving each individual the chance to develop at the highest level his own resources, meaning that there has to be a different goal for every student (Fedeli, 2016; Pennazio, 2017). While respecting general and specific learning aims, personalizing didactics involves a high variety of methodologies and didactical strategies, which are fundamental to promote the abilities and the successful development of each individual (e.g. using didactical mediators as diagrams, being careful to learning styles, modelling interventions depending on the starting level...) (Baldacci, 2005; Fedeli, 2016; Pennazio, 2017).

Individualization, on and educational and didactical level, refers to a series of strategies and interventions that are designed by teachers, depending on students' characteristics and finalized to getting to common goals, that are set in advance and thought of as fundamental; on the other hand, personalization considers singularity as fundamental (i.e. differences between students); characteristics as potential resources and personal growth are highlighted (Sandrone, 2012).

The educational and didactical approach that is typical of personalization does not ignore, if necessary, interventions led to individualization, as they might be fundamental to a specific process: the autonomous growth of the individual. Specific severe and complex conditions of disability might require specific paths with aims that are far away from those listed in the ordinary curriculum, as in the case of personal or social independence (Ianes, 2005). Every scenario involves an educational offer which has to be a mixture between goals and individualized activities (always linked to curricular activities) on one side and personalized aims, which respond to individual development needs, on the other.

\section{Rethinking the curriculum in an inclusive way}

When thinking about changing the curriculum into a more inclusive one, it is important to consider common paths where everyone has the chance to take part according to his abilities and functioning level, rather than focus on personalization through the development of diversified paths (Fedeli, 2016).

Inclusion is possible starting from micro and macro-design, with the creation of the meeting point through the Individualized Educational Plan (Piano educativo personalizzato, PEI), which is required for students certified by Law 104/92 and the Personalized Didactical Plan (Piano 
didattico personalizzato, PDP), required for the other types of special needs (e.g. learning disabilities, social or cultural disadvantage), together with the promotion of and inclusive didactics that uses for All strategies in the structure of all the educational paths offered. On a design level, inclusion involves work on several areas, as shown in Table 1.

Table 1 - Different design levels of inclusion

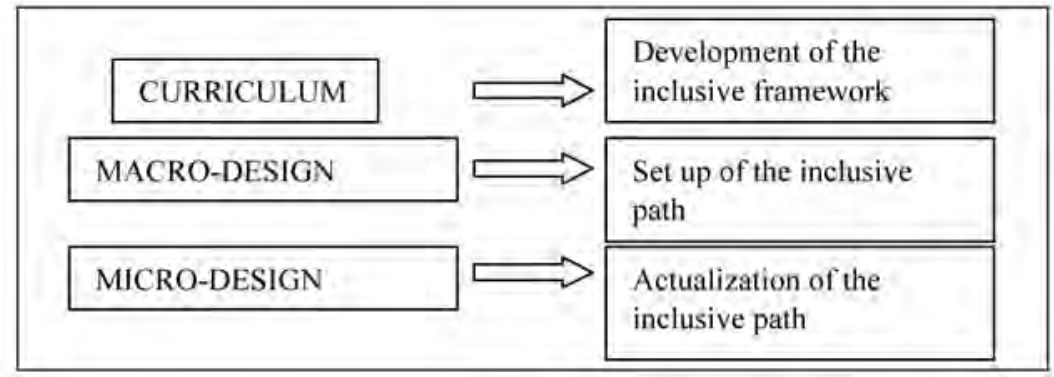

In the phase of curriculum development the framework takes shape, as an inclusive container; in the macro-design phase there is the specification of the inclusive path in a long term perspective; in micro-design it is visible the actualization of the inclusive path in a shorter timeframe (e.g. a class).

When focusing on the curriculum aspect (of our interest) with an inclusive perspective, it becomes the result of a sharing process between professional figures with different competencies. Specifically, the specialized teacher should be enabled to take part to the development of the curriculum, working side by side with the regular teacher, even when the particular topic does not directly involve students with disabilities certified by Law $104 / 92$ but other special needs that do not specifically require a qualified teacher. The availability of such a figure is fundamental, as it provides the inclusive didactical competences that allow him to give useful advice in relation to several aspects that need to be considered to make that curriculum available to every student. For example, he can lead to the core of every subject, focusing on the meaning and the value depending on the type of special needs present in the school; he can give an explanation of the meaning of specific goals in relation to characteristics of students with special needs; lastly, he can guide in the selection of key competencies linked to an inclusive environment on which focus, linking them to subjects (Table 2). 
Table 2 - Key steps in the development of an inclusive curriculum

\begin{tabular}{|l|l|}
\hline SELECTING KEY CONCEPTS & $\begin{array}{l}\text { The meaning and values in relation to specific } \\
\text { special needs }\end{array}$ \\
\hline COMPETENCIES' GOALS & $\begin{array}{l}\text { Defining the ways through which assigning } \\
\text { meaning in relation to certified students }\end{array}$ \\
\hline SELECTING KEY COMPONENTS & $\begin{array}{l}\text { Defining the competencies needed for the } \\
\text { development of and inclusive environment }\end{array}$ \\
\hline
\end{tabular}

Thinking about the development of an inclusive curriculum, it is fundamental to define that the actions that need to be undertaken are different depending on the area of the special educational need on which we focus (Table 2).

Table 3 - Different approaches in designing the curriculum depending on the type of special need

\begin{tabular}{|l|l|l|}
\hline $\begin{array}{l}\text { DISABILITY } \\
\text { (L. 104/92) }\end{array}$ & $\begin{array}{l}\text { LEARNING DISABILITIES } \\
\text { (L. 170/10) }\end{array}$ & $\begin{array}{l}\text { OTHER SPECIAL NEEDS } \\
\text { (D.M. 2012 C.M. 2013) }\end{array}$ \\
\hline $\begin{array}{l}\text { FOR KEY CONCEPTS GOALS } \\
\text { AND COMPETENCIES }\end{array}$ & $\begin{array}{l}\text { SAME KEY CONCEPTS GOALS } \\
\text { AND COMPETENCIES }\end{array}$ & $\begin{array}{l}\text { SAME KEY CONCEPTS GOALS } \\
\text { AND COMPETENCIES }\end{array}$ \\
$\begin{array}{l}\text { Focus on the ones that can } \\
\text { be coherent with the PEI-Life } \\
\begin{array}{l}\text { Project. Find the meaning of } \\
\text { that key concept and goal can } \\
\text { have in relation to the type of } \\
\text { disability. } \\
\text { (Light-Medium-Severe) }\end{array}\end{array}$ & $\begin{array}{l}\text { Anticipate which didactical } \\
\text { strategies will have to be/will be } \\
\text { able to be carried out. }\end{array}$ & $\begin{array}{l}\text { Anticipate which didactical } \\
\text { strategies will have to be/will be } \\
\text { able to be carried out. }\end{array}$ \\
\hline
\end{tabular}

As highlighted in the reported table, regarding students with special needs in relation to key concepts and goals, the focus is on the ones that are coherent with the PEI-Life Project; the meaning is related to the type of disability presented (Light-Medium-Severe).

It is different in the case of students with learning disabilities or other types of special needs, as in this case it is only possible to anticipate the possible didactical strategies.

The development of the actual inclusive project happens during macrodesign and is realized in micro-design.

On a macro-design level every subject teacher working on inclusion, should start from some questions that can help him to better define the path that will be presented to the class: what is important for the student to learn in 
relation to my subject? Will everyone be able to understand the contents that I have selected? What competencies do they need to get there? Starting from these thoughts, the teacher is led to focus on three dimensions: adaptation (of the goals, the materials, the contents) following what already planned in the curriculum; means and strategies.

Regarding adaptation, the teacher should already consider at the macrodesign phase which will be the most functioning adaptation (substitution, facilitation, simplification, breakdown of the key components...) (Ianes, 2006), in order to develop the content that will be debated and the possible challenges that could stem from it (in the input access, its elaboration and understanding and the output required) (Ianes, 2006).

At the beginning, it has to be evaluated if applying the first, second or both levels of adaptation. The first level is the substitution of inputs components and action (not simplification) and it requires the same goal together with the input presentation using several codes or styles and suggesting different ways in which perform the action (Ianes, 2006). In this way, there is a focus on accessibility, the chance of receiving information or act in different ways (e.g. If the aim is reading and comprehension, a blind student can receive Braille material, a student with learning disabilities or foreigner can have the audio version. If the aim is answering to some questions, a blind student can have Braille writer and a student with learning disabilities a word processor) (Ianes, 2006). The second level of adaptation is facilitation and it focuses on a recontextualization of the aim in real environments rather than on its change; using interactive contexts such as learning groups, with different stimulations (colours, pictures, tables, metacognitive strategies, self-instructions) and longer timeframes (Ianes, 2006).

In the cases where it is not possible to follow those modalities, it is necessary to work on learning times and frames that involve the adoption of the third level of adaptation, simplification, in which the complexity of the aim is decreased through one of its components (comprehension, elaboration, answer), changing the language or the intricacy of communication modality, replacing some routines (as calculations that can be done through a calculator), simplifying criteria for the correct execution of the action(more errors and imprecisions are allowed) (Ianes, 2006).

Only in cases of extreme participation complexity noticed by the student, it is possible to consider the breakup of key components of the subject, focusing on its cognitive processes to understand goals that are participated, accessible and significant (Ianes, 2006).

In the same way, the instruments should be thought of in their compensative function (laptop, tablet, maps, software, apps), as well as the best exceptive measures and didactical strategies (cooperative work, tutoring, metacognitive didactics). 
This three-level observation which widely develops on the macro-design level and is defined in a real and detailed way on a micro-design level, even if starting from difficulties manifested by some students, it can be generalized to the whole class.

This logic enables to overcome difficulties linked to the creation of personalized paths for every student, considering that it leads to the formation of common but diversified paths, in which every student will have the opportunity to find different access ways (e.g. reading, listening, visualizing), different paths to follow, several instruments and more product to design.

\section{Conclusion}

At the present time it is crucial to consider an inclusive curriculum, but there are only few educational experiences that were able to develop curricula independently from traditional rules and closer to the dynamics that are typical for the idea of inclusion. There are two fundamental levels that need to be considered around this topic: how to make the curriculum inclusive and achievable at the same time; how to make the curriculum a promotor of inclusive culture.

Both aspects have been understood and accepted in the different sections (dimension C) of the Index of Inclusion, an instrument developed in the United Kingdom with the aim of evaluating the degree of inclusion in schools. Among the various aspects, it is clear the need to rethink the curriculum to ignite a real change and there are two critical aspects: the reference to what will be taught, to the designed learning activities and the way those are structured in thematic areas; the reference to what is learnt through experience both in and out of school (Dovigo, 2014). The aim is to start a reflection in the relation between learning and teaching, focusing on the experience of the students. From those ideas emerges the need to bring closer what is taught and what is learnt, checking the more informal aspects of the curriculum, the values that become a way to show the involvement towards the community and deciding the contents of the curriculum itself.

On an international level, several changes to the curriculum have been introduced (Dovigo, 2014, p. 73), often following the Index values, even if more traditional. Despite the importance given to traditional topics, sessions respond to already firm expectations with a balance between the traditional curriculum and a second more specific one.

It is understandable that structuring an inclusive curriculum is an open discussion, on which it is necessary to focus future studies. 


\section{References}

Arcangeli L., Bartolucci M. e Sannipoli M. (2016). La percezione della qualità dei processi inclusivi: il punto di vista della scuola. In Ianes D., a cura di, Evolvere il sostegno si può e si deve. Trento: Erickson.

Baldacci M. (2005). Personalizzazione o individualizzazione? Trento: Erickson.

Bochicchio F., a cura di (2017). L'agire inclusivo della scuola. Logiche, metodologie e tecnologie per insegnanti ed educatori. Lecce: Libellula, Tricase,

Booth T. \& Ainscow M. (2008). L'Index per l'inclusione. Promuovere l'apprendimento e la partecipazione nella scuola. Trento: Erickson.

Booth T. \& Ainscow M. (2015). Nuovo Index per l'inclusione. Percorsi di apprendimento e partecipazione a scuola. Roma: Carocci.

Calvani A. (2014). Come fare una lezione efficace. Roma: Carocci Faber.

Canevaro A. (2007). L'integrazione scolastica degli alunni con disabilità. Trento: Erickson.

Cigman R., ed. (2007). Included or Excluded. The challenge of the mainstream for some SEN children. London and New York: Routledge.

Clough P. \& Corbett J. (2000). Theories of Inclusive Education. A student's guide. London: Paul Chapman Publishing.

Cook L. \& Friend M. (1995). Co-Teaching: Guidelines for creating effective practices. Focus on Exceptional Children, 28, 3: 1-16.

Davis P. \& Florian L. (2004). Teaching strategies and approaches for pupils with special educational needs: A scoping study. London: Department for Education and Skills.

D'Alessio S. (2011). Inclusive Education in Italy. A Critical Analysis of the Policy of Integrazione Scolastica. Rotterdam: Sense Publishers.

D'Alessio S. \& Watkins A. (2009). International Comparisons of Inclusive Policy and Practice - are we talking about the same thing? Research in Comparative and International Education, 4, 3: 233-249.

D’Alessio S., Watkins A. \& Donnelly V. (2010). Inclusive education across Europe: the move in thinking from integration to inclusion. Revista de Psicología y Educación, 1, 5: $109-127$.

D'Alessio S. \& Donnelly V., ed. (2013). Organisation of provision to support the development of inclusive education. A literature review. European Agency for Development in Special Needs Education, Odense (DK). Retrievable online at: https://www.european-agency.org/publications/reviews/organisation-of-provisionto-support-inclusive-education-2013-literature-review [documento consultato il 20 novembre 2017].

Dieker L.A. \& Murawski W.W. (2003). Co-teaching at the secondary level: Unique issues, current trends, and suggestions for success. The High School Journal, 86: $1-13$.

Dovigo F. (2008). L'Index per l'inclusione: una proposta per lo sviluppo inclusivo della scuola. In Booth T., Ainscow M., L'Index per l'inclusione. Promuovere l'apprendimento e la partecipazione nella scuola. Trento: Erickson.

Dovigo F., a cura di (2014). Nuovo Index per l'inclusione. Percorsi di apprendimento e partecipazione a scuola. Roma: Carocci. 
Dyson A. (1999). Inclusion and inclusions: Theories and discourses in inclusive education. In Daniels H. \& Garner P., eds., World Yearbook of Education 1999: Inclusive Education. London: Kogan

Fedeli D. (2016). Individualizzazione e Personalizzazione (glossario tematico). In Aa.Vv., Il PDP Come e cosa fare. Bologna: Giunti Edu.

Friend M., Cook L., Hurley-Chamberlain D.A. \& Shamberger C. (2010). Coteaching: an illustration of the complexity of collaboration in special education. Journal of Educational and Psychological Consultation, 20, 1: 9-27.

Gately S. \& Gately F. (2001). Understanding co-teaching components. Teaching Exceptional Children, 33, 4: 40-47.

Ianes D. (2005). Bisogni Educativi Speciali e inclusione. Valutare le reali necessità e attivare tutte le risorse. Trento: Erickson.

Ianes D. (2006). La speciale normalità. Trento: Erickson.

Ianes D. (2007). Dal Piano educativo individualizzato al Progetto di vita. In Ianes D., Cramerotti S., a cura di, Il Piano educativo individualizzato. Progetto di vita. Trento: Erickson.

Mitchell D., ed. (2005). Contextualizing Inclusive Education. Evaluating old and new international perspectives. London and New York: Routledge.

Palmieri C. (2006). Dal Pei al Progetto di Vita: la prospettiva della cura educativa. Handicap \& Scuola, 126, testo disponibile al sito: http://digilander.libero.it/ handicapscuola/pag.9-12.pdf [documento consultato il 25 marzo 2017].

Pennazio V. (2017a). Formarsi a una cultura inclusiva. Un'indagine dei bisogni formativa degli insegnanti nel corso di specializzazione per le attività di sostegno. Milano: FrancoAngeli.

Pennazio V. (2017b). Il progetto inclusivo della scuola: l'Index for inclusion. In Bochicchio F., a cura di, L'agire inclusivo della scuola. Logiche, metodologie e tecnologie per insegnanti ed educatori. Lecce: Libellula, Tricase.

Pennazio V. (2017c). Tecnologie inclusive. In Bochicchio F., a cura di, L'agire inclusivo della scuola. Logiche, metodologie e tecnologie per insegnanti ed educatori. Lecce: Libellula, Tricase.

Ravaud J.F.\& Stiker H.J. (2000). Les modèles de l'inclusion et de l'exclusion à l'épreuve $\mathrm{du}$ handicap. Lère partie: les processus sociaux fondamentaux d'exclusion et d'inclusion. Handicap, Revue de sciences humaines et sociales, 86: 1-17.

Rossi P.G., Giaconi C., a cura di (2016a). Micro-Progettazione pratiche a confronto. Propit, EAS, Flipped Classroom. Milano: FrancoAngeli.

Rossi P.G., Giaconi C. (2016b). La progettazione educativa come azione. In Perla L., Riva M.G., a cura di, L'agire educativo. Brescia: La Scuola.

Sandrone G., a cura di (2012). Pedagogia speciale e personalizzazione. Tre prospettive per un'educazione che "integra”. Brescia: La Scuola.

Tremblay P. (2012). Inclusion scolaire. Dispositifs et pratiques pédagogiques. Paris: de Boeck. 